\title{
PROPOSTA DE INTERVENÇÃO PARA MELHORIAS NA GESTÃO COMERCIAL DE UMA INDÚSTRIA
}

\author{
INTERVENTION PROPOSAL FOR IMPROVEMENTS IN THE COMMERCIAL \\ MANAGEMENT OF AN INDUSTRY
}

\author{
Liliane da Silva Castanhetti \\ Mestranda em Administração \\ Universidade Estadual do Oeste do Paraná - UNIOESTE \\ Cascavel, PR - Brasil \\ lilianecastanhetti@gmail.com \\ Michelli Julhian Abegg Ceolin \\ Mestranda em Administração \\ Universidade Estadual do Oeste do Paraná - UNIOESTE \\ Cascavel, PR - Brasil \\ abeggalipr@gmail.com \\ Claudio Antonio Rojo \\ Doutor em Engenharia de Produção \\ Universidade Federal de Santa Catarina - UFSC \\ Cascavel, PR - Brasil \\ rojo_1970@hotmail.com
}

\begin{abstract}
Resumo: O objetivo deste trabalho foi apresentar uma proposta de intervenção de melhorias na gestão comercial de uma fábrica de vidros localizada no Paraná. Trata-se de um relato técnico que, após a realização de encontros para conhecer a estrutura da empresa, conversas com o coordenador do setor comercial e a aplicação da ferramenta, possibilitou uma visão mais clara do ambiente em que a empresa está inserida e do seu modelo de negócios. Para a coleta de dados foram realizados encontros onlines e presenciais, com aplicação de um diagnóstico e das ferramentas de análise estratégica Business Model Canvas e Matriz SWOT, além da análise da estrutura da empresa. Diante das situações levantadas com a aplicação das ferramentas foi possível identificar oportunidades de melhorias a fim de auxiliar a empresa em seu desenvolvimento da área comercial, como principais propostas, foram sugeridas: a padronização da identidade visual da empresa, criação de material de apoio para os vendedores e clientes, ampliação do envolvimento nas redes sociais e site, implementação do pós-vendas, plano de capacitação da equipe de vendas, e ações de engajamento da equipe.
\end{abstract}

Palavras-chave: Estratégia. Business model canvas. SWOT.

Abstract: The objective of this work was to present an intervention proposal for improvements in the commercial management of a glass factory located in Paraná. It is a technical report that, after holding meetings to learn about the company's structure, conversations with the coordinator of the commercial sector and the application of the tool, enabled a clearer view of the environment in which the company operates and of its business model. For data collection, online and face-to-face meetings were held, with the application of a diagnosis and the Business Model Canvas and SWOT Matrix strategic analysis tools, in addition to the analysis of the company's structure. In view of the situations raised with the application of the tools, it was possible to identify opportunities for improvement in order to assist the company in its development of the commercial area, as main proposals, the following were suggested: the standardization of the company's visual identity, creation of support material for salespeople and customers, increased involvement in social networks and the website, post-sales implementation, sales team training plan, and team engagement actions.

Keywords: Strategy. Business model canvas. SWOT.

\section{$\underline{\text { Cite como }}$}

American Psychological Association (APA)

Castanhetti, L. S., Ceolin, M. J. A., \& Rojo, C. A. (2021, jul./dez.). Proposta de intervenção para melhorias na gestão comercial de uma indústria. Revista Inovação, Projetos e Tecnologias - IPTEC, São Paulo, 9(2), 239-254. https://doi.org/10.5585/iptec.v9i2.20032. 


\section{Introdução}

Tendo em vista as mudanças nas dinâmicas do mercado, as empresas precisam buscar alternativas para se adaptar a este ambiente. O planejamento estratégico é uma forma da empresa conseguir encontrar respostas sobre como ela está inserida nesse cenário e de qual forma ela pretende se adaptar a esse novo ambiente. O planejamento auxilia os gestores a prever problemas para conseguir contorná-los e resolver os já existentes (Teixeira, Dantas, \& Barreto, 2015).

Com a alta concorrência e o grande acesso à informação disponível aos consumidores, as empresas precisam inovar para conseguir conquistar os seus clientes através de um canal adequado para chegar até eles. Tendo em vista que um dos maiores objetivos das empresas é o lucro, a equipe de vendas é primordial para a busca desse propósito. Atualmente, as vendas deixaram de serem vistas como finalizadas apenas com o pedido, o seu processo é um ciclo contínuo envolvendo pré e pós-vendas. Portanto, isso requer organização e planejamento na força de vendas (Berta, Passarin, Santos, \& Daleaste, 2019).

A equipe comercial é o canal de ligação entre a empresa e o mercado (Maia, Futami, de Oliveira, \& Hurtado, 2016). Portanto, este departamento possui um papel essencial na adaptação da organização às novas tendências do mercado. Gradativamente têm ocorrido mudanças na forma que o processo de vendas é conduzido, graças às novidades tecnológicas que aprimoraram as análises e às mudanças nas técnicas de vendas. Neste ambiente, os vendedores necessitam estar motivados para alcançar bons resultados e os seus gestores precisam se preocupar com a preparação adequada de sua equipe para melhorar a eficiência nas vendas (Saldanha, 2018).

Para auxiliar no processo de planejamento estratégico comercial há ferramentas como o SWOT e Canvas que possibilitam uma visão sistemática do modelo de negócio da empresa e seu ambiente interno e externo (Trevisan, Fialho, \& Coronel, 2018). A análise do Canvas contempla quatro áreas principais de um modelo de negócio: clientes, oferta, infraestrutura e viabilidade financeira (Osterwalder \& Pigneur, 2011). A matriz SWOT ajuda a fornecer aos tomadores de decisão a posição da empresa perante o cenário escolhido, por meio da análise interna de suas forças (Strengths) e fraquezas (Weaknesses), e de suas características extrínsecas, isto é, suas oportunidades (Opportunities) e ameaças (Threats) do ambiente de fora da organização (Fernandes, 2012).

Tais ferramentas já foram utilizadas para a construção de um modelo de negócios de uma empresa da área de educação em marketing digital (Loureiro, Caldeira, Souza, \& Arcari, 
2017), na elaboração um plano de negócios de uma micro cervejaria artesanal no Maranhão (Silva, Pinheiro, Serra, Rodrigues, \& Vieira, 2018), para o planejamento de um negócio inovador de nutrição com microalgas em Santa Catarina (Behling, Pereira, \& Marinho, 2019) e para auxiliar no aumento de vendas de uma microempresa de soluções para espelho ponto (Presrlak, Endo, Kato-Cruz, \& Bulhões, 2021).

Tendo em vista a eficácia apresentada em estudos anteriores, este relato técnico tem por objetivo utilizar as ferramentas de planejamento estratégico SWOT e Canvas para auxiliar o setor comercial da Indústria de Vidros Alfa, com o intuito de realizar um diagnóstico e fornecer propostas visando contribuir no engajamento e na identidade da equipe comercial, a fim de melhorar o atendimento com os seus consumidores.

Este relato está estruturado em cinco seções, além da presente introdução. Em seguida, é apresentada a metodologia adotada, na sequência a aplicação prática, seguida da análise e discussão dos resultados. Por fim, encerra-se com as considerações finais, e as referências utilizadas no estudo.

\section{Metodologia}

O presente relato técnico resulta do trabalho para conclusão da disciplina de Oficina I do Mestrado Profissional em Administração da Universidade Estadual do Oeste do Paraná. O objetivo deste trabalho foi realizar um diagnóstico e fornecer propostas visando contribuir com melhorias na gestão comercial de uma indústria. A coleta de dados deu-se através de visita à indústria para conhecer seu ambiente de trabalho e o seu processo produtivo, além de reuniões com o coordenador do setor comercial e da análise das mídias da empresa. Para sigilo dos dados, este trabalho adotou o nome fictício de "Alfa" para a indústria estudada.

A empresa havia relatado em um primeiro contato a necessidade de melhorias no setor comercial. Trata-se de uma equipe que está em processo de mudanças e necessita de alternativas para melhorar o atendimento ao cliente. Para a realização do diagnóstico, foi realizada uma reunião com o coordenador comercial para levantar informações iniciais e as principais necessidades da empresa. Nesta primeira reunião, foram realizados questionamentos sobre pontos chave: produtos, clientes, vendedores, oferta, marketing, sobre a equipe comercial como um todo e sua rotina.

Um segundo encontro foi realizado para conhecer as instalações da empresa, a fim de analisar o ambiente de trabalho e o processo produtivo da indústria. Na terceira reunião com o coordenador comercial foram aplicadas as ferramentas Business Model Canvas e SWOT. A 
partir do diagnóstico realizado, foram propostas alternativas para melhorar os processos do setor comercial. Com a conclusão deste trabalho, serão realizadas posteriormente mais reuniões envolvendo outros membros da equipe comercial, para auxiliar na aplicação das ações e acompanhamento da proposta de intervenção, sendo atividades vinculadas à disciplina de Oficina II do Mestrado Profissional em Administração.

\section{Aplicação prática}

Nesta seção, apresenta-se a caracterização da empresa foco deste estudo, além dos resultados obtidos nas reuniões e visitas, através do diagnóstico, análise SWOT, Canvas e análise das mídias da empresa.

\subsection{Caracterização da empresa}

A indústria de vidros Alfa foi fundada em 2014 no estado do Paraná. Tem por objetivo atuar no mercado de vidros curvos e planos para máquinas pesadas, máquinas agrícolas e projetos personalizados. A empresa dispõe de técnicos e mão de obra especializada, visando a melhor qualidade na fabricação dos produtos. Ademais, busca estabelecer uma relação transparente com os clientes, oferecendo uma política de garantia para os produtos ofertados.

A empresa vende por atacado e varejo para todo o Brasil. As vendas ocorrem através de atendimento interno por telefone e internet. Possui atualmente uma carteira com mais de 5 mil clientes, contando com cerca de 46 colaboradores e um faturamento bruto anual de aproximadamente 7 milhões de reais.

\subsection{Diagnóstico}

Através da primeira reunião com o coordenador comercial, foi possível levantar informações sobre alguns pontos chave: produtos, clientes, vendedores, oferta, marketing, sobre a equipe comercial como um todo e sua rotina.

No que tange aos produtos, a empresa fabrica vidros curvos e planos atendendo dois mercados principais: máquinas pesadas do setor de construção civil, como retroescavadeira, escavadeira hidráulica, entre outros, e o mercado de máquinas agrícolas, tais como colheitadeira, pulverizador, trator etc. Dentro desses mercados, há as divisões e categorias de máquinas, sendo que no mercado agrícola é mais simples, sendo cada marca possui um determinado número de modelos de máquinas. 
Em relação aos projetos especiais, a empresa atende alguns projetos de vidros para o setor automotivo, no caso de carros antigos que o vidro já saiu da linha de produção da fábrica ou projetos de automóveis em desenvolvimento. Na construção civil, a empresa também atende projetos realizados por arquitetos, como vidros para sacadas, por exemplo, além de protetores salivar para buffet de restaurantes. Porém, o coordenador relatou que há alguns projetos de vidros curvos que a empresa não consegue atender devido ao tamanho das peças, como peças muito grandes ou uma curva muito acentuada, por exemplo.

Quanto aos clientes, o mercado pode ser dividido em venda B2B (Business-to-business) para empresas que revendem autopeças, empresas prestadoras de serviços como terraplenagem, e para indústrias fabricantes de cabines de máquinas agrícolas e pesadas, e a venda B2C (Business-to-consumer) para pessoas físicas que são proprietárias de máquinas, como produtores rurais, por exemplo.

De acordo com o entrevistado, a empresa possui uma carteira sólida dos clientes e está realizando um trabalho de análise da carteira. Essa análise servirá para entender o tipo de peça vendida, sazonalidade dessa peça, para qual tipo de cliente é vendida, qual o retorno desse cliente, isto é, quanto tempo ele demora para comprar novamente. Um próximo estudo será realizado visando entender o cliente, motivações de compra, demora para retorno de compra, qual tipo de cliente, qual localidade do cliente etc. As informações já levantadas são qual a quantidade de clientes, sazonalidade e valor médio de vendas que os vendedores precisam para atingir suas metas.

Uma das ferramentas implantada em setembro de 2020 foi o CRM (Customer Relationship Management) realizando a integração com os dados já existentes do sistema ERP (Enterprise Resource Planning) utilizado pela empresa. O CRM foi escolhido para auxiliar o gerenciamento da comunicação com o cliente e para o acompanhamento das vendas pelos responsáveis do setor comercial. O entrevistado relatou que os vendedores ainda enfrentam dificuldades para se adaptar a essa nova ferramenta.

Atualmente, a equipe comercial é composta por oito vendedores internos, dois coordenadores, sendo um responsável por dar auxílio aos vendedores relacionado à parte técnica e de negociação e o outro trabalha com a análise de carteira de clientes e de mercado, sendo este último que participou das reuniões. Além disso, a equipe conta com uma assistente responsável pelo acompanhamento dos pedidos de vendas, dando suporte aos vendedores. Foi relatado que a empresa tem por objetivo contratar mais quatro vendedores até junho de 2021 .

Em relação aos benefícios ofertados para os funcionários, identificou-se que a empresa possui uma remuneração melhor que empresas de maior porte. Além disso, a empresa fornece 
o almoço, vale alimentação e plano odontológico. Logo, há motivações financeiras para os vendedores. Entretanto, o coordenador relatou que falta engajamento da equipe como um todo, falta entender que os vendedores não estão ali só tirando pedido. É preciso trabalhar em prol da empresa e entender que as mudanças têm o objetivo de melhorar o trabalho de todos.

Há três perfis de vendedores no momento: os vendedores com mais de cinco anos de empresa que possuem uma carteira de clientes mais consolidada, também chamados de clientes curva A, ou seja, clientes mais fidelizados que possuem frequência de compras. Dentre os vendedores mais novos, há os que já estão trabalhando há seis meses e os de três meses. Os vendedores novos iniciam com uma carteira de clientes que foi dividida igualmente, cerca de 150 a 200 clientes cada. Relatou que há uma rotatividade baixa no setor, pois é tranquilo e não há muita pressão em relação a cobranças de metas.

$\mathrm{O}$ atendimento desses vendedores aos clientes, ocorre por telefone, e-mail, Skype e WhatsApp, raramente ocorre atendimento presencial. A empresa possui um site institucional, porém é pouco explorado para atrair clientes. Em relação a mídias sociais, na entrevista foi observado que a empresa não utiliza esse tipo de mídia para comunicação com os clientes, porém em uma pesquisa prévia, foram identificados alguns perfis com o nome da empresa que aparentemente foi criado de forma autônoma por parte dos vendedores e que não estão em consonância com a identidade visual da empresa.

Os clientes inativos, por sua vez, são aqueles que não possuem registro de contato há mais de três meses e ficam livres na base de clientes do sistema para a prospecção dos vendedores. Além disso, quando um cliente novo ou inativo entra em contato com a empresa, ele é passado de forma aleatória para um dos vendedores realizarem o atendimento.

Quando ocorre demissões e/ou contratações de vendedores e os clientes passam a integrar a carteira de outro vendedor, anteriormente a empresa enviava uma carta informativa. Porém, com o tempo perceberam que era inviável. Quando o vendedor realiza o primeiro contato com o cliente, eles são orientados a se apresentarem de acordo com um checklist padrão elaborado pela coordenação. Antes da ligação, o vendedor deve se inteirar sobre informações do segmento, mercado que o cliente está inserido, tipo de peça que ele trabalha etc. Geralmente, os vendedores novos não têm experiência com esse tipo de venda, eles são vendedores "genéricos".

O checklist para orientação dos novos vendedores segue uma ordem: primeiro, atendimento a clientes potenciais; segundo, orientar o vendedor como utilizar o sistema e como fazer a correta abordagem de vendas; terceiro, o cliente que procura a empresa - Padrão de atendimento. 
Quando um novo vendedor inicia as suas atividades, ele recebe uma orientação de forma oral sobre os tipos de máquinas, o que atendem, estados, tipos de vidro, carga tributária, tabelas etc. Após essa primeira orientação, já começa a contatar os clientes. Entretanto, não há um material físico para ficar disponível para consulta do vendedor em caso de dúvidas iniciais. $\mathrm{O}$ material de apoio que todos os vendedores possuem para auxiliar nas vendas é uma planilha com o catálogo da empresa. $\mathrm{O}$ vendedor procura na planilha pelo modelo da máquina ou pelo código original informado pelo cliente. Caso não encontre, o outro coordenador auxilia, pois possui conhecimento tácito.

O entrevistado relata que é necessário melhorar o atendimento com o cliente, fazer com que os vendedores tenham um padrão de atendimento que demonstre a identidade da empresa, que tenha a "cara da indústria Alfa". Ele informa que, no momento, a motivação das compras é a qualidade do produto e a flexibilidade da empresa, como a não exigência de compra mínima, por exemplo. O coordenador disse que, por enquanto, o objetivo principal é estruturar o setor de vendas. Tendo em vista que a empresa já possui uma carteira sólida de clientes, eles estão buscando trabalhar nesta base e não focar na prospecção de novos clientes.

Em relação ao acompanhamento do pedido (lead time) depende de qual produto foi comprado. Se tem estoque da peça até 2 dias e se vai para a produção, até 7 dias. $\mathrm{O}$ vendedor tem uma tabela de acompanhamento, lançamento (início) e expedição (por meio de uma planilha de Excel) - mas já está sendo agrupado os dados em um sistema que irá facilitar. Quanto ao pós-vendas, atualmente é o vendedor quem faz essa parte. Porém, não é realizada de forma estruturada, fazendo com que os vendedores percam muito tempo realizando esse acompanhamento e contato.

Em relação à forma que os produtos são ofertados, a empresa não possui um setor de marketing, pois o seu foco é atender as revendas de peças e acreditam que se fosse realizado um trabalho em divulgação traria mais clientes pessoa física. Porém, eles já possuem uma carteira consolidada que pretende realizar um trabalho com eles antes de buscar novos consumidores. Os clientes chegam até a empresa geralmente através de indicações ou pela prospecção dos vendedores, raramente vêm através da internet. Ademais, a empresa não possui um catálogo para enviar aos clientes. $\mathrm{O}$ entrevistado disse que há dificuldades para elaborar esse material, pois a empresa possui muitos itens.

No segundo encontro realizado presencialmente foi possível ver na prática como ocorrem todos os processos e conhecer o ambiente de trabalho. A indústria é localizada no térreo e no segundo andar fica o escritório e a sala de reuniões. O setor comercial fica localizado 
no mesmo escritório que o setor administrativo. As mesas dos vendedores ficam próximas ao dos coordenadores e da assistente. A sala de reuniões ainda está sendo aprimorada.

Uma outra informação levantada no encontro presencial é que a capacidade produtiva irá aumentar com a instalação de novos fornos, e que além disso o processo produtivo está passando por melhorias através de uma consultoria fornecida pelo SENAI. Por tanto, será preciso alinhar as vendas com o aumento produtivo planejado. Sendo que uma das dificuldades do setor comercial, é justamente a conversão de orçamento em vendas, que atualmente está abaixo do esperado.

No terceiro encontro, foi realizado com o coordenador o SWOT e o CANVAS, no qual foi possível reforçar algumas informações passadas na primeira reunião e levantar mais pontos sobre a empresa. As informações levantadas pelo CANVAS podem ser observadas através da Figura 1:

\section{Figura 1.}

\section{Canvas da Indústria Alfa}

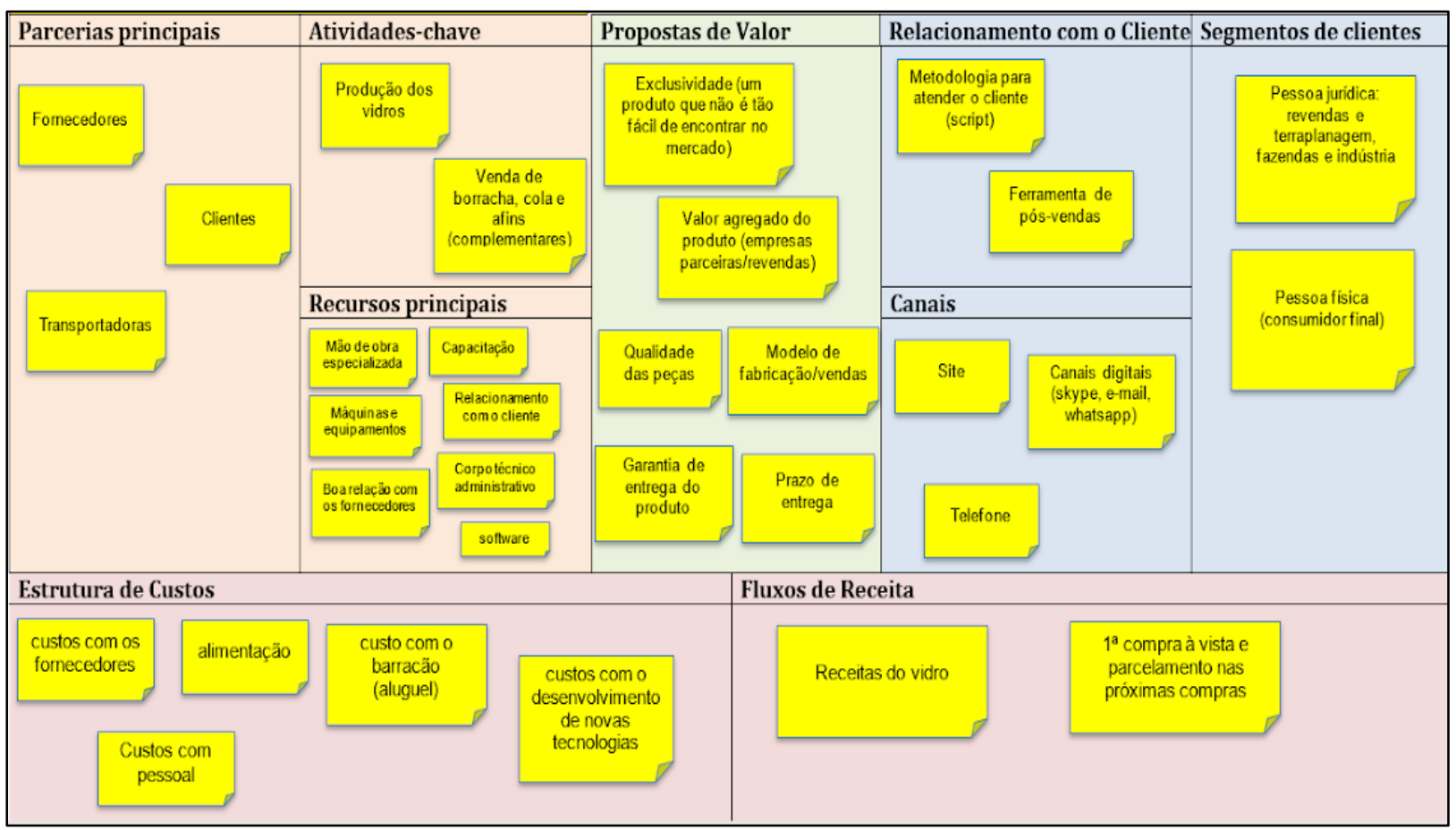

Fonte: Elaborado pelos autores (2021).

De acordo com a Figura 1, em relação ao segmento de clientes, assim como havia relatado na primeira reunião, a empresa atende dois segmentos de clientes: as pessoas jurídicas composto por revendas de autopeças, terraplanagem, fazendas e indústrias e o outro composto pelas pessoas físicas geralmente proprietárias de máquinas, produtores rurais. $\mathrm{O}$ foco da 
empresa são as revendas de autopeças e as indústrias. Quanto aos demais clientes, a empresa realiza o atendimento caso elas entrem em contato, não fazem parte das prospecções.

A proposta de valor da empresa envolve a exclusividade, por se tratar de um produto que não se encontra facilmente no mercado nacional. Para as revendas, eles conseguem comprar e revender os vidros com uma margem de lucro significativa. Outro ponto, é a qualidade do produto que já foi elogiado por consumidores. Um atrativo também é o modelo de fabricação e vendas que não exige uma quantidade mínima de compra. A empresa também fornece garantia de produção e de transporte do produto. Além disso, o prazo de entrega de 2 dias caso a peça esteja em estoque, para conseguir colocar a peça na fila de embalagem, e 7 dias para peças que precisam ser fabricadas são prazos competitivos se comparados a outras indústrias do mercado.

Os canais de venda utilizados pela empresa são digitais no caso do Skype, e-mail e WhatsApp, além do telefone e do site. Entretanto, o site da empresa é pouco utilizado, pois eles não têm a intenção de investir nesse canal, pois não veem necessidade dessa estratégia no momento.

Quanto ao relacionamento com o cliente, o entrevistado relatou que eles possuem uma metodologia para atender o cliente, uma espécie de script. Ademais, estão tentando estruturar o pós-vendas com o auxílio da implantação do CRM. Em relação aos fluxos de receita, a principal fonte de receita da empresa é a venda de vidros. O método de pagamento é a primeira compra à vista e as demais podem ser parceladas, caso não apresentem restrições de crédito.

Os recursos principais da empresa são a mão de obra especializada e as máquinas e equipamentos necessários para a fabricação dos vidros. O bom relacionamento com os fornecedores é essencial, ainda mais neste momento de pandemia que o mercado tem enfrentado problemas de abastecimento (Paiva \& Miguel, 2020). O corpo técnico administrativo é importante para a saúde financeira e fiscal da empresa. A capacitação de toda equipe é de suma importância para a atualizar o atendimento da empresa perante o mercado. $\mathrm{O}$ software serve para administrar os setores financeiro, comercial e produção. $\mathrm{O}$ bom relacionamento com o cliente é a chave para manter as vendas e o crescimento da empresa.

As atividades-chave da indústria são a fabricação de vidros e a venda de produtos complementares para a instalação dos vidros como borracha, cola e afins. As parcerias principais da empresa são com os fornecedores para não ter problemas de abastecimento e prejudicar a produção. As parcerias com as transportadoras são essenciais para conseguir bons preços com os fretes já que a empresa vende para todo o Brasil. A parceria com os clientes é importante para manter a fidelidade e a constância das vendas. 
A estrutura de custos é composta pelos custos com salários e comissões dos colaboradores, os custos com o desenvolvimento de novas tecnologias, como a fabricação de novos fornos, os custos de compras com os fornecedores e o custo com o aluguel do barracão.

Na Figura 2 apresenta-se as informações levantadas durante a reunião com a aplicação do SWOT:

\section{Figura 2.}

SWOT da Indústria Alfa

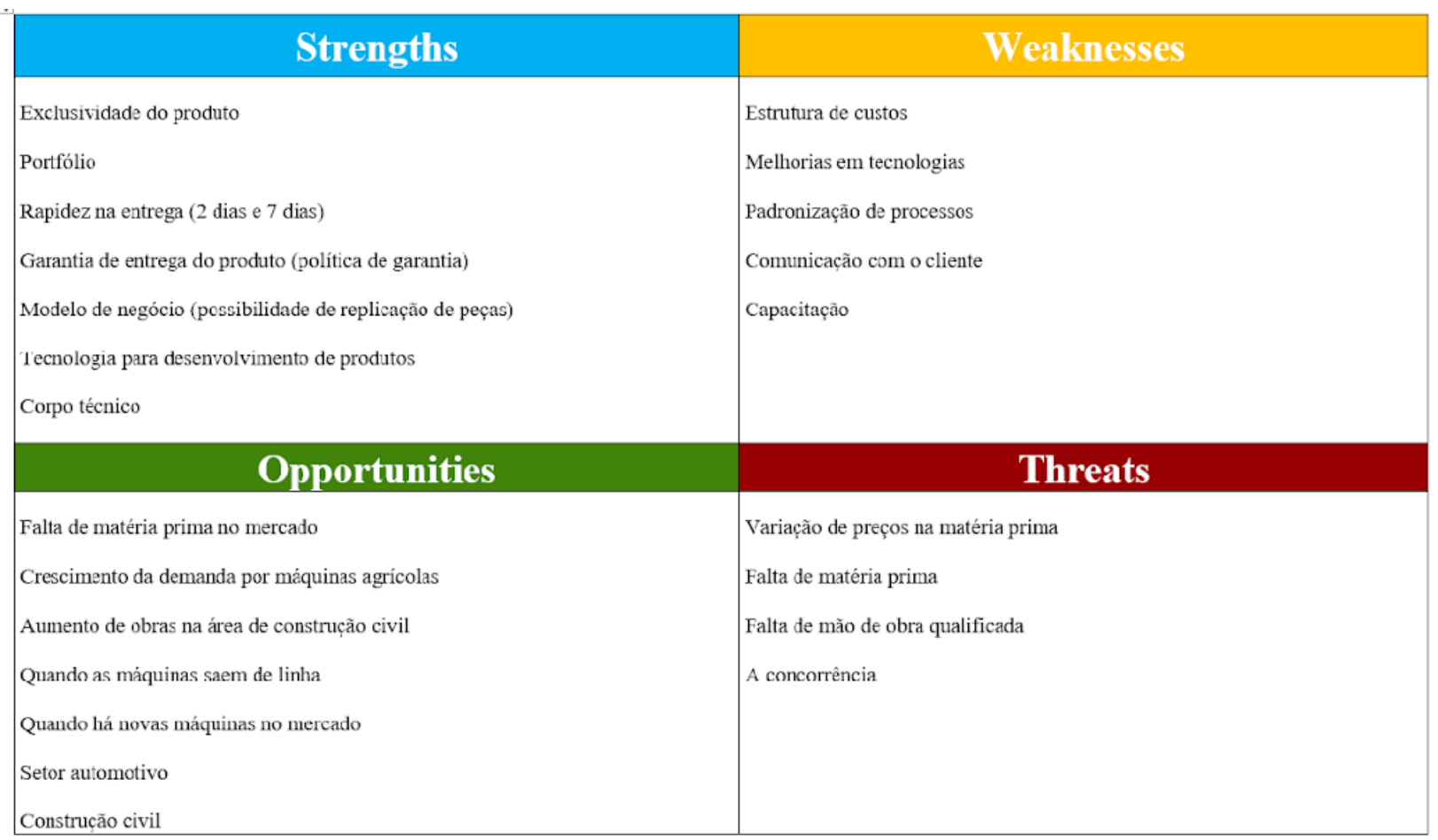

Fonte: Elaborado pelos autores (2021).

De acordo com a Figura 2, em relação às forças (Strengths) da empresa, isto é, as vantagens internas da organização, o entrevistado relatou que está a exclusividade do produto, por não se encontrar com tanta facilidade fabricantes desse tipo de peça. A empresa possui um vasto portfólio de peças para várias marcas e modelos de máquinas. A rapidez na entrega da peça também é um diferencial, a empresa é competitiva em comparação a outros fabricantes do mercado.

A política de garantia de fabricação e de transporte é uma segurança na compra para os clientes. O modelo de negócio torna-se um diferencial ao possibilitar a replicação de peças. Ademais, a empresa dispõe de tecnologia e corpo técnico para o desenvolvimento de peças que ainda não estejam em seu portfólio e para projetos especiais. 
No que tange às fraquezas (Weaknesses), ou seja, as desvantagens internas da empresa, a sua estrutura de custos ainda precisa de melhorias para reduzir seus custos e, consequentemente, deixar seus preços mais competitivos no mercado. A indústria precisa de mais atualizações tecnológicas em seu processo produtivo. Além disso, a organização precisa de uma melhor padronização de seus processos internos. A comunicação com o cliente precisa ser aprimorada para uma melhor identidade da empresa perante seu mercado consumidor. Para tal, a empresa ainda requer disponibilizar cursos de capacitação para a sua equipe comercial.

Quanto às suas oportunidades (Opportunities) que são as forças externas que podem influenciar positivamente a organização, no momento devido a pandemia e os problemas de abastecimento do mercado, graças as parcerias mantidas com os seus fornecedores, a empresa consegue ter estoque de matéria-prima e ter vantagem diante de seus concorrentes. Além disso, o crescimento do agronegócio no país e, consequentemente, o aumento da demanda por máquinas agrícolas é uma oportunidade para a indústria Alfa aumentar seu portfólio de produtos com os novos modelos de máquinas no mercado e conseguir mais clientes.

$\mathrm{Na}$ área de construção civil, o aumento das obras é uma oportunidade tanto para fornecer vidros para as máquinas pesadas, quanto para realizar projetos especiais residenciais. Outro ponto, é quando algumas máquinas ou carros saem da linha de fabricação da marca, os clientes acabam buscando indústrias que fabricam sob medida, como a Indústria Alfa. Quando as marcas de máquinas pesadas e agrícolas lançam novos modelos é uma oportunidade para a empresa aumentar o seu portfólio de produtos. Ademais, o setor automotivo e da construção civil também é um mercado que pode ser melhor explorado pela empresa.

Os aspectos negativos que podem comprometer a vantagem competitiva da empresa que seriam as suas ameaças (Threats), no caso da Indústria Alfa uma delas é a constante variação dos preços das matérias-primas que fazem com que a empresa precise realizar reajustes em seus preços e isso causa desgaste em seu relacionamento com os clientes. O risco de desabastecimento diante de crises também é uma ameaça. Há também a dificuldade de conseguir mão de obra qualificada para o setor comercial. Além disso, as indústrias concorrentes que possuem uma capacidade produtiva maior e preços competitivos são uma ameaça na conquista de clientes. 


\section{Análise e discussão dos resultados}

Com o levantamento das informações por meio das reuniões e visitas, foi possível analisar os pontos nos quais a empresa precisa melhorar em seu setor comercial e, a partir disso, levantar propostas para que a empresa consiga aprimorar os seus processos.

Quanto à estrutura física, a empresa poderia explorar mais recursos visuais. No escritório onde está localizado o setor comercial poderia ter recados e mapas dos processos que envolvem o setor, o que também pode ser disponibilizado em arquivos digitais para a consulta pelo computador e celular. Ademais, o mesmo poderia ser realizado na sala de reuniões, onde poderiam ser expostos estes mapas de processos de todos os setores.

Em relação à comunicação com o cliente, com a finalidade de padronizar o atendimento e fazer com que a equipe comercial tenha uma identidade associada à empresa, torna-se necessário a elaboração de um manual para auxiliar o atendimento dos vendedores. Este material poderia ser dividido de acordo com as particularidades dos segmentos dos clientes da empresa, demonstrando quais as abordagens mais adequadas para cada caso. Isto pode ser um suporte sobretudo para os vendedores mais novos, os quais necessitam se adaptar ao mercado da Indústria Alfa, pois geralmente são vendedores que não possuem experiência no mercado de vidros para máquinas pesadas e agrícolas. Além disso, pode auxiliar para que os vendedores não sejam tão dependentes do auxílio da coordenação durante os atendimentos rotineiros.

Além disso, para que os vendedores consigam se adaptar ao uso de novas ferramentas, como o CRM por exemplo, e possam aprimorar seu atendimento com os consumidores é de suma importância a realização de treinamentos. Os cursos ou palestras podem ser realizados à distância ou presencialmente com especialistas da área. É importante realizar um cronograma para a programação destes treinamentos, em virtude do planejamento financeiro para a disponibilidade de recursos, quanto para agendar com o responsável por ministrar o curso/palestra e para organizar a melhor data para não prejudicar as vendas ao deixar os vendedores ocupados durante o treinamento.

Além da sugestão de treinamentos com pessoas externas, pode-se explorar o conhecimento dos colaboradores da empresa. No caso do coordenador responsável pela análise de mercado, ele poderia realizar treinamentos repassando informações relevantes que possam auxiliar os vendedores com o fechamento das vendas e também apresentar à equipe comercial a análise de mercado do período, novidades e projeção para o mês.

Com o comprometimento dos vendedores na alimentação de informações nas ferramentas como o sistema ERP e no CRM pode possibilitar aos gestores o acompanhamento 
das ações de venda. Um dos problemas relatados é a baixa conversão dos orçamentos em vendas. Para mudar esse panorama, aliando as informações dos vendedores de suas ações, os gestores podem monitorar os orçamentos e cobrar para que os vendedores entrem em contato com o cliente e verifique se ele recebeu o orçamento, se tem dúvidas, se há algum dificultador para o fechamento do pedido (prazo, valor, entrega), e se for o caso, identificar qual o motivo de não fechamento da venda. Assim, posteriormente pode-se trabalhar os pontos que estão dificultando a conversão de vendas. Além desse levantamento, pode-se realizar campanhas de vendas visando o aumento de vendas e ativação de clientes inativos.

A fim de melhorar o relacionamento com o cliente, do início da prospecção até a entrega final do produto, há uma oportunidade de implantação do pós vendas na empresa. Essa implantação tem o objetivo de padronizar o atendimento e trazer tranquilidade e segurança ao cliente, pois o cliente será acompanhado em todas as fases de permanência e contato com a organização.

Outra sugestão a fim de concatenar todas essas propostas, é criar um plano de ação com as ações que a empresa achar pertinentes dentre todas sugeridas. Nesse plano de ação é importante que conste a ação, quem irá executar, onde, quando, e resultados esperados. Posteriormente recomenda-se o acompanhamento e ajustes das ações se necessário.

Tais ações propostas estão dentro do que a literatura chama de comunicação interna e endomarketing. Para que os colaboradores se tornem comprometidos com a entrega de produtos e serviços de qualidade, precisam receber informações que lhes permitam compreender e aceitar seus papéis individuais e coletivos nesse processo, sendo de suma importância a comunicação interna como um instrumento de promoção da qualidade (Almeida, Souza \& Mello, 2010).

A utilização do endomarketing pode trazer benefícios para a empresa por meio da integração das áreas e com a comunicação interna, fazendo com que o conhecimento seja compartilhado entre os colaboradores criando uma gestão do conhecimento. Os impactos do endomarketing podem ser verificados através de métricas de prazos, depoimento de funcionários, na transformação do conhecimento tácito em conhecimento explícito, entre outros. O importante é que as estratégias envolvam toda a organização, de forma que os colaboradores se sintam parte do processo (Silva \& Estender, 2018).

Para promover o engajamento da equipe e contribuir nas mudanças propostas é necessário a conscientização dos mesmos através de treinamentos, palestras e cursos além do monitoramento dos gestores no dia a dia. Os treinamentos para a melhor comunicação com os consumidores, os manuais para dar suporte às vendas, ferramentas como o CRM, a implantação dos pós-vendas e o plano de ação podem ser caracterizados como estratégias de marketing 
interno, isto é uma forma de mobilizar os vendedores para conquistar os clientes. Enquanto os recursos como reuniões e palestras motivacionais e os recursos visuais como os mapeamentos de processos podem ser enquadrados como estratégias de endomarketing, ou seja, formas de melhorar o engajamento e a motivação da equipe internamente (Almeida, Souza \& Mello, 2010).

Foi levantado que a empresa não possui um departamento de marketing e não tem por objetivo investir nessa área, sobretudo o marketing digital, pois não pretendem atrair consumidores finais, porque seu foco são as revendas de auto peças. Entretanto, marketing digital pode oferecer várias vantagens para empresas desse segmento. As oportunidades proporcionadas pelo marketing digital muitas vezes são negligenciadas pelas empresas que focam em vendas B2B, seja por falta de conhecimento ou por não estabelecerem um planejamento estratégico claro nesta área. Práticas simples como a divulgação de produtos podem resultar em aumento da notoriedade e geração de leads nas empresas B2B (Barbosa, Santos \& Filipe, 2020).

Portanto, sugere-se para a empresa que seja realizado um planejamento para aprimorar e padronizar a identidade visual da empresa nas mídias sociais - Instagram e Facebook - e site. Apesar da empresa não ter intenção de atrair os consumidores finais, ter um marketing digital de qualidade pode ajudar a empresa a ter mais credibilidade com o mercado, tanto com empresas que revendem auto peças como com as indústrias de cabines. Uma estratégia de marketing com um bom planejamento e administração pode gerar reconhecimento da marca (brand awarenes) necessário para que a mesma ganhe participação nos mercados-alvo e alcance os objetivos propostos no plano (Ballarin, 2021).

\section{Conclusões}

Este estudo teve como objetivo apresentar uma proposta de intervenção para melhorias na gestão comercial de uma indústria de vidros, localizada no Paraná. Para atingir o objetivo, foi realizada a aplicação de ferramentas de análise estratégica, diagnóstico, Matriz SWOT e CANVAS. Com os dados coletados, foi realizada uma análise pelas autoras, que através da experiência profissional e conhecimentos adquiridos na pós graduação stricto sensu, puderam elaborar uma proposta com diversas sugestões de ações de melhorias para auxiliar a Empresa Alfa em seu processo de desenvolvimento no setor comercial.

O presente relato técnico e seus resultados não podem ser generalizados a todas as empresas, pois as empresas possuem realidades diferentes. Desse modo é preciso verificar a 
situação real da empresa para propor ações adequadas de acordo com seu ramo de atuação, tamanho, região, etc. Cabe diagnosticá-las e proceder com intervenção precisa e de acordo com a realidade.

Como limitações do estudo, compreende-se essa diferença que há entre empresas, não podendo ser aplicado ações genéricas e sim de acordo com cada realidade. Com relação a publicações de relatos técnicos na área de administração, nota-se que são incipientes, limitando assim a busca de trabalhos semelhantes para usar como referência.

\section{Referências}

Almeida, L. M. D. S., Souza, L. G. M. D., \& Mello, C. H. P. (2010). A comunicação interna como um instrumento de promoção da qualidade: estudo de caso em uma empresa global de comunicação. Gestão \& Produção, 17(1), 19-34.

Ballarin, R. R. (2021). A aplicação de ferramentas do marketing digital como elemento estratégico em MICR. Trabalho de conclusão de curso (Administração) - Universidade Federal de São Paulo - Escola Paulista de Política, Economia e Negócios, Osasco, São Paulo, Brasil.

Barbosa, B., Santos, C. A., \& Filipe, S. (2020). Um estudo exploratório sobre a adoção de social media marketing por empresas B2B. ICIEMC Proceedings, (1), 29-37.

Behling, G., Pereira, D. G., \& Marinho, S. V. (2019). Uma Gota no Oceano e Vários Desafios para a Ocean Drop. Revista de Administração Contemporânea, 436-453.

Berta, E. M., Passarin, P., Santos, P. P., \& Daleaste, J. C. (2019). Gestão Empresarial: um estudo do setor comercial em uma empresa do segmento metal-mecânico. Anais Centro de Ciências Sociais Aplicadas/ISSN 2526-8570, 111-127.

Fernandes, D. R. (2012). Uma visão sobre a análise da Matriz SWOT como ferramenta para elaboração da estratégia. Revista de Ciências Jurídicas e Empresariais, 57-68.

Loureiro, G. C., Caldeira, A., Souza, S. A., \& Arcari, V. (2017). Criação de valor com base em inovação a custos reduzidos: a experiência de construção de um modelo de negócios empreendedor. Fórum Liberdade Econômica, 1-14.

Maia, B. I., Futami, A. H., de Oliveira, M. A., \& Hurtado, B. A. (2016). Estrutura de Vendas nas Organizações de Conformação a Frio do Norte de Santa Catarina. Espacios, 37(14), $1-9$.

Osterwalder, A., \& Pigneur, Y. (2011). Business model generation: inovação em modelos de negócios. Rio de Janeiro: Alta Books.

Paiva, V., \& Miguel, P. L. (2020). Como lidar com fornecedores diante da pandemia. GVExecutivo, 15-17. 
Presrlak, M. I., Endo, G. Y., Kato-Cruz, É. M., \& Bulhões, R. (2021). Análise estratégica e propostas de intervenção: um caso prático em uma microempresa em Cascavel/PR. Revista de Casos e Consultoria, 1-20.

Saldanha, W. B. (2018). Avaliação de desempenho na área comercial: proposta de um modelo de avaliação específica para profissionais de vendas. Trabalho de Conclusão de curso. Centro Universitário UNIVATES, Lajeado, RS, Brasil.

Silva, P. B. R., \& Estender, A. C. (2018). O Impacto do Endomarketing nas Organizações. Revista Inovação, Projetos e Tecnologias-IPTEC, 6(1), 19-35.

Silva, R. F., Pinheiro, E. M., Serra, M. C., Rodrigues, A. L., \& Vieira, A. C. (2018). Plano de negócios de uma microcervejaria artesanal, Maranhão. Revista Perspectivas Online: Exatas \& Engenharias, 01-16.

Teixeira, C. A., Dantas, G. G., \& Barreto, C. A. (2015). A importância do planejamento estratégico para as pequenas empresas. Revista eletrônica científica da FAESB, 104123.

Trevisan, L. V., Fialho, C. B., \& Coronel, D. A. (2018). Propostas de implantação das ferramentas Canvas e análise SWOT em uma empresa de pequeno porte. Revista Inteligência Competitiva, 35-52. 